\title{
Update on the Autoimmune Pathology of Multiple Sclerosis: B-Cells as Disease-Drivers and Therapeutic Targets
}

\author{
H.-Christian von Büdingen Arumugam Palanichamy Klaus Lehmann-Horn \\ Brady A. Michel Scott S. Zamvil \\ Department of Neurology, University of California San Francisco, San Francisco, Calif., USA
}

\section{Key Words}

Multiple sclerosis · B-cells · B-cell-depleting therapy

\begin{abstract}
Background: Collectively, research on the role of B-cells in the pathogenesis of multiple sclerosis (MS) illustrates how translational medicine has given rise to promising therapeutic approaches for one of the most debilitating chronic neurological diseases in young adults. First described in 1935, the experimental autoimmune/allergic encephalomyelitis model is a key animal model that has provided the foundation for important developments in targeted therapeutics. Summary: While additional B-cell therapies for MS are presently being developed by the pharmaceutical industry, much remains to be understood about the role played by $\mathrm{B}$-cells in MS. The goal of this review is to summarize how Bcells may contribute to MS pathogenesis and thereby provide a basis for understanding why B-cell depletion is so effective in the treatment of this disease. Key Messages: Bcells are key players in the pathogenesis of MS, and their depletion via B-cell-targeted therapy ameliorates disease activity. Clinical Implications: In 2008, data from the first CD20-targeting B-cell depleting therapeutic trials using rituximab in MS were published. Since then, there has been a large body of evidence demonstrating the effectiveness of B-cell depletion mediated via anti-CD20 antibodies. Intense
\end{abstract}

research efforts focusing on the immunopathological relevance of B-cells has gained significant momentum and given rise to a constellation of promising therapeutic agents for this complex B-cell-driven disease, including novel anti-CD20 antibodies, as well as agents targeting CD19 and BAFF-R.

(c) 2015 S. Karger AG, Base

\section{Multiple Sclerosis - A Brief Overview}

Multiple sclerosis (MS) is the most common chronic neurological disease in young adults, affecting about 2.5 million people worldwide. In countries populated by Northern Europeans and their descendants, the incidence is about $7 / 100,000$, and the prevalence is about $120 / 100,000$ [1]. The incidence of MS seems to have increased over the last century, particularly in women, leading to a female:male sex ratio of 3:1 [2]. The peak age of onset is between 20 and 40 . At disease onset, $~ 80 \%$ of patients are diagnosed with relapsing-remitting MS (RRMS); over time, about $60 \%$ of RRMS patients will develop secondary progressive MS. About 25\% never experience sustained neurological disability, whereas a smaller percentage become severely disabled a short time after disease diagnosis. Pathologically, MS is characterized by chronic CNS inflammation accompanied by demyelin-

\section{KARGER 125}

2015 S. Karger AG, Base

0014-3022/15/0734-0238\$39.50/0
$\mathrm{H}$-Christian von Büdingen, MD

Department of Neurology

University of California, San Francisco, 675 Nelson Rising Ln

San Francisco, CA 94158 (USA)

E-Mail Hans-Christian.vonBuedingen@ucsf.edu 
ation, gliosis, and axonal loss. Axonal degeneration is believed to be ultimately responsible for progressive neurological dysfunction. The most widely accepted view of MS pathogenesis includes autoimmune-mediated myelin injury in a susceptible host. MS behaves as a complex genetic trait [3], and exposure to infectious, climatic and other environmental variables likely have a considerable effect on an individual's risk for developing MS. Diseasespecific, immune-modulatory therapies became available in the mid-to-late 1990s; currently, seven substances are approved for the treatment of MS (interferon- $\beta 1$, glatiramer acetate, mitoxantrone, natalizumab, fingolimod, dimethyl fumarate, teriflunomide). These compounds have been extensively studied and are discussed elsewhere in the literature. In this review article, we will focus on B-cells, their immunological properties relevant to MS, and how these functions are targeted by the B-cell depleting therapeutic strategies currently in development.

\section{B-Cells: Drivers of MS}

B-cells can exert effector functions as antigen-presenting cells, by cytokine and antibody production, and they participate in the formation of ectopic lymphoid tissues (fig. 1). The strongest evidence to date for B-cells playing a crucial role in MS immune pathology stems from studies evaluating the effect and efficacy of anti-CD20 B-celldepleting therapies such as rituximab, ocrelizumab, and ofatumumab [4-7]. Interestingly, the initial impetus for B-cell depleting therapy was to remove autoantibodyproducing plasma cells after multiple experimental autoimmune encephalitis (EAE) studies had demonstrated the critical roles of antibody responses in the development of CNS demyelination [8-11]. However, since the late 1990s, it has become increasingly appreciated that antigen presentation by B-cells is a necessary step for triggering autoimmunity against the CNS myelin oligodendrocyte glycoprotein [12-14]. B-cells can provide activation/effector mechanisms, and can assume proinflammatory, anti-inflammatory and/or regulatory roles. To date, the exact target antigens of pathogenic B-cell responses in MS remain unknown, despite our knowledge that disease-associated B-cells result from antigen-driven affinity maturation. Needless to say, not all B-cells in MS patients support detrimental autoimmunity. Therefore, being able to clearly differentiate pathologically relevant from normal B-cells in the future will pave the way for treatments with enhanced therapeutic precision and im-

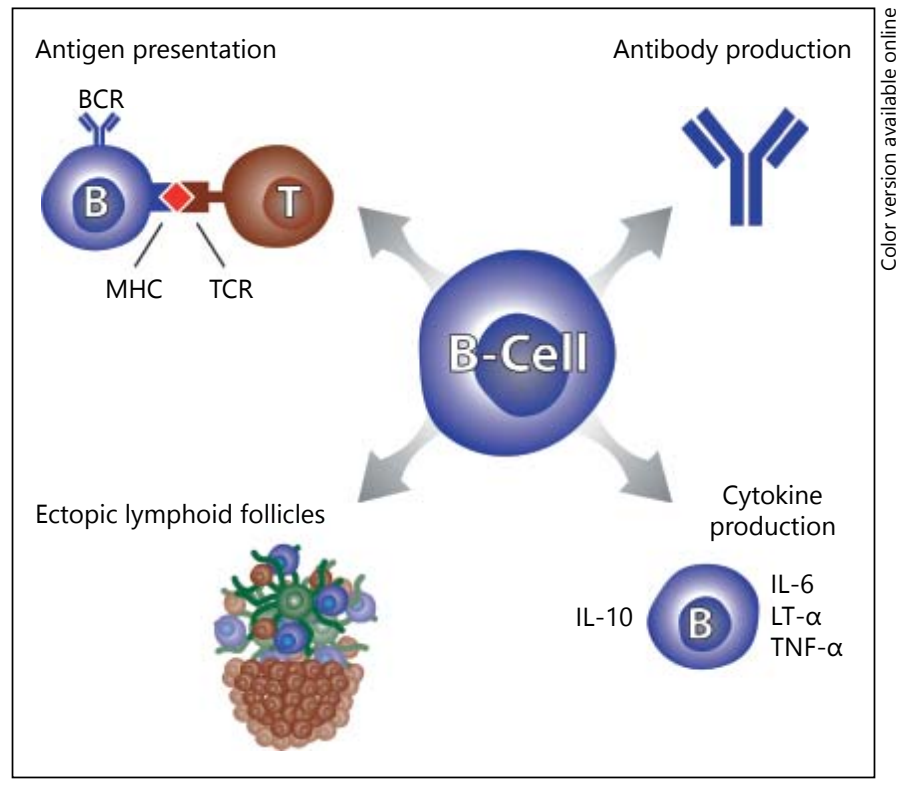

Fig. 1. B-cell functions. Depicted are the basic immunological functions performed by B-cells as relevant to MS immune pathology. Autoantigen presentation was shown to be the key B-cell function driving experimental CNS autoimmunity in myelin-oligodendrocyte-induced EAE. Antibodies have long been hypothesized to play a role in MS; for example, clonal antibodies can be found as oligoclonal bands (OCB) in cerebrospinal fluid (CSF). Ectopic lymphoid follicles are tertiary lymphoid tissues that become established at sites of inflammation. In MS, lymphoid follicle-like structures have been found associated with meningeal tissues. Cytokine production by B-cells can support regulatory (IL10) and proinflammatory T-cell functions (IL-6, LT- $\alpha$, TNF- $\alpha$ ); cytokine production by B-cells can occur following recognition of specific antigens or in an antigen-independent fashion. See text for detailed explanations.

proved safety profiles, thereby bringing us closer to personalized therapy.

In the following paragraphs, we discuss the B-cell functions that have been demonstrated to be involved in the immune pathogenesis of MS, as well as additional functions that may likely be involved in MS immune pathology. We will focus mainly on data from human studies but will include experimental animal data where appropriate.

\section{The Peripheral B-Cell Compartment in MS}

There is ample evidence that peripheral B-cell responses are closely involved in the immune pathology of MS through proinflammatory mechanisms, bystander activation, or through regulatory functions. Under normal circumstances, B-cell tolerance is necessary to control autoimmunity that can randomly develop during 
early B-cell development [15] or even during targeted immunity against foreign pathogens [16]. Central B-cell tolerance, which reduces the autoimmune potential of Bcells developing in the bone marrow, appears to be intact in the majority of MS patients; conversely, B-cell tolerance mechanisms that regulate the autoimmunity of Bcells circulating between peripheral lymphoid tissues seems to be defective [17]. Cervical lymph nodes have been described as possible sites supporting CNS-directed autoimmunity in both humans [18] and mice [19].

Memory B-cells serve as highly efficient antigen-specific antigen-presenting cells (APC) [20, 21]. In this regard, myelin-reactive memory B-cells can be found in the peripheral blood of MS patients [22]. Memory B-cells express high levels of CD20; they are effectively depleted and repopulate slowly following treatment with antiCD20 targeting monoclonal antibodies [23], coinciding with sustained suppression of MS disease activity [24]. In MS, B-cells were shown to secrete increased levels of IL-6 compared to healthy controls; this proinflammatory bias was not observed in returning B-cells 12 months after Bcell-depleting therapy [25]. Given that the repopulating $\mathrm{B}$-cell compartment is mainly composed of mature naïve and immature B-cells [26], it is likely that the increased IL-6 production in MS patients is a function associated with antigen-experienced memory B-cells. Memory Bcells are also effective supporters of T-cell immune mechanisms; their depletion reduces IL-17 production by peripheral blood lymphocytes, providing further evidence for the role of B-cells in supporting proinflammatory $\mathrm{T}$ helper 17 cell (Th17) responses [13, 25]. Furthermore, Bcells from MS patients were shown to respond to nonspecific activating stimuli such as $\mathrm{CpG}$ or IFN- $\gamma$ with an exaggerated proinflammatory cytokine profile [27]. Accordingly, the proinflammatory functions of B-cells in MS can also occur in an antigen-independent fashion, by way of bystander activation of T-cells, a mechanism that explains the association of MS relapses with systemic infections $[28,29]$.

In humans and mice, IL-10 secreting B-cells (B10 cells) exert regulatory roles by suppressing T-helper 1 (Th1) differentiation $[30,31]$ and by downregulating TNF- $\alpha$ production in monocytes [32]. Conflicting data exists regarding the B-cell subpopulation responsible for IL-10 secretion. One study found IL-10 expressing B-cells among activated memory B-cells, suggesting that B10 cells perform antigen-specific regulatory functions [32]; increased numbers of IL-10 producing B-cells were reported in patients with autoimmune disease although most of the MS patients in this study had received treatment with im- mune-suppressive or immune-modulatory therapies [32]. Conversely, another study reported that IL- 10 secretion is mainly a function of naive B-cells [21] and that a switch from regulatory B10 cells to proinflammatory Bcells may occur as B-cells transition from the naïve to the memory phenotypes [21]. In EAE, B10 cells inhibit autoimmune T-cell responses, an effector function that is dependent on IL-21 and CD40-mediated interaction with T-cells [33]. Interestingly, under certain circumstances, therapeutic B-cell depletion in EAE may also eliminate regulatory $\mathrm{B}$-cells and result in exacerbation of disease activity [14]. To date, disease worsening as a direct response to CD20-targeting B-cell-depleting therapy has not been observed in humans; however, an increased proinflammatory monocytic phenotype has been described in some MS patients after treatment with rituximab [34].

We recently demonstrated that in MS, clonally related B-cells provide an antigen-specific and immunologically active link between the periphery and cerebrospinal fluid $[35,36]$ and that oligoclonal bands (OCB)-producing Bcells are present not only in the CNS but also in peripheral blood [37]. Therefore, antigen-stimulated B-cells provide an active immune axis bridging the CNS and the periphery and they may undergo immune stimulation in both compartments [35-37], further supporting the important pathological role of peripheral B-cell immunity in MS (fig. 2).

\section{$B$-Cells in the CNS}

A growing body of evidence has not only established the CNS as the target tissue of autoimmunity in MS but has identified sub-compartments (i.e., brain parenchyma, cerebrospinal fluid, meningeal tissue) that reflect immunological activity, supporting B-cell affinity-maturation, proliferation, and terminal differentiation to antibody-producing plasma cells. B-cells are commonly found in MS lesions, albeit predominantly in active lesions and at significantly lower numbers compared to Tcells [38]. Lymphoid B-cell follicle-like structures featuring characteristics of germinal centers have been observed in the cerebral meninges of secondary progressive MS patients [39] and are associated with cortical neuronal loss and demyelination $[40,41]$. While the pathological importance of such ectopic B-cell follicles as drivers of CNStargeted autoimmunity remains to be fully understood, the presence of $\mathrm{CD} 35+$ follicular dendritic cells and proliferating B-cells, together with expression of the B-cellattracting chemokine CXCL13 and of the B-cell-activation factor (BAFF) suggest that active immune responses occur in meningeal tertiary lymphoid tissues in second- 
Fig. 2. B-cells provide an immunologically active axis between the periphery and CNS. Naiive B-cells emerge from the bone marrow (1) and undergo initial antigen-training and affinity maturation in peripheral germinal centers (GC). Memory B-cells arising from GCs can be further stimulated in peripheral lymphoid tissues and/or migrate to the CNS compartment (2) where they participate in, and establish immunologically active sites in MS lesions (A) and pial meningeal tissues (B). An immunological continuum and 'circulation' (3) of antigen-experienced B-cells also involves the cerebrospinal fluid (CSF) compartment represented by schematic lateral ventricles in blue (C). Clonal and clonally related Bcell receptors suggesting ongoing antigenstimulation can be detected in all three CNS-sites (i.e., lesions, meninges, CSF) and in the periphery, suggesting MS disease-driving immunity to be active on both sides of the blood-brain barrier. The CSF (C) also contains oligoclonal bands (OCB) in the majority of MS patients, another sign of antigen-driven stimulation of B-cells to differentiate into antibody producing plasmablasts or plasma cells. B-cells are shown in blue, T-cells in green. See text for further details.

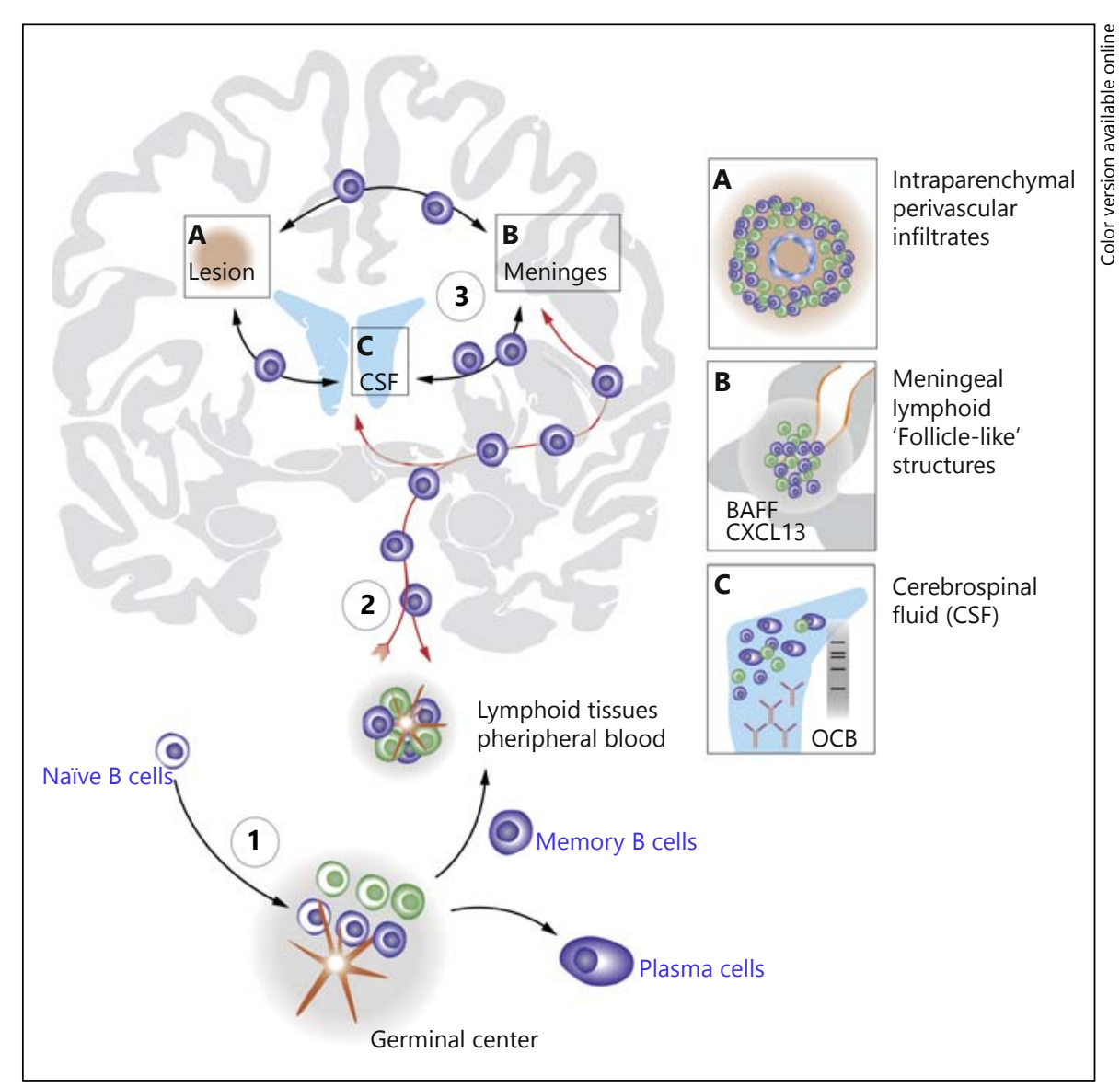

ary progressive MS patients [39, 42]. Furthermore, CXCL13 and BAFF have also been described in MS lesions $[43,44]$ where these factors could mediate local Bcell recruitment and maturation at sites of active demyelination. B-cells present in MS CNS and CSF are clonally expanded [45-47] and IgG class-switched [48, 49], and their immunoglobulin genes are somatically hypermutated and appear to be subject to intrathecal affinitymaturation [36, 47, 50-52], which is an additional evidence to support the involvement of active B-cell immune mechanisms. The fact that overlapping B-cell repertoires expressing related Ig-VH sequences were found in MS brain parenchyma, meningeal lymphoid follicles, CSF, and the periphery $[35,36,53,54]$, suggests an intrathecal immunological continuum that may be exposed to immune-stimulation on both sides of the blood-brain barrier (fig. 2).

Memory B-cells in the CSF display upregulation of costimulatory molecules [55] suggesting active $B$ - and T-cell interactions. Different stages of B-cell development are present in CSF [55] and CSF plasma cells are producers of soluble clonal IgG $[56,57]$, further supporting antigendriven B-cell immune responses to be active intrathecally. It has been repeatedly shown that antigen-experienced Bcell subsets predominate in the CSF and CNS. Accordingly, $>90 \%$ of B-cells in the CSF carry the memory B-cell marker CD27 and a fraction of CSF B-cells express CD138 and/or CD38, supporting the presence of mechanisms that stimulate the maturation of clonally activated memory B-cells into antibody-producing plasmablasts and plasma cells [58]; the levels of CD27-IgD+ naïve B-cells are significantly lower in the CSF compared to blood [59].

To date, the pathological relevance of antibodies in MS remains unclear despite the intrathecal presence of clonal IgG (OCB) and IgM [60-62] and significant IgG deposits in some demyelinating MS lesions [63]. The rapid response to B-cell depleting therapy, leaving antibody levels nearly unchanged $[5,6]$, has led to the speculation that antibodies play a less important pathogenic role. However, CNS-directed autoantibodies require a permissible inflammatory environment [8] or at the very least a functional complement system to exert their pathogenic func- 
Table 1. Biologics targeting B-cells or B-cell-activating factors

\begin{tabular}{|c|c|c|c|}
\hline Biologic & Molecular characteristics & Targets & Effects in MS \\
\hline Rituximab & $\begin{array}{l}\text { murine/human chimeric monoclonal } \\
\text { IgG1 }\end{array}$ & $\begin{array}{l}\text { CD20 } \\
\text { B cells: see fig. } 3 \\
\text { CD20+ T cells }\end{array}$ & $\begin{array}{l}\text { reduced MRI measures of disease activity }[4,5] \\
\text { reduced relapse rate }[4,5] \\
\text { reduced intrathecal B-cells }\end{array}$ \\
\hline Ocrelizumab & humanized (90\%) monoclonal IgG1 & $\begin{array}{l}\text { CD20 } \\
\text { B cells: see fig. } 3 \\
\text { Effect on CD } 20+\text { T cells } \\
\text { not yet known }\end{array}$ & $\begin{array}{l}\text { reduced MRI measures of disease activity [6] } \\
\text { reduced relapse rate [6] }\end{array}$ \\
\hline Ofatumumab & fully human monoclonal IgG1 & $\begin{array}{l}\text { CD20 } \\
\text { B cells: see fig. } 3 \\
\text { Effect on CD } 20+\text { T cells } \\
\text { not yet known }\end{array}$ & reduced MRI measures of disease activity [7] \\
\hline Atacicept & $\begin{array}{l}\text { recombinant fusion protein with } \\
\text { extracellular domain of TACI receptor } \\
\text { and Fc domain of human Ig }\end{array}$ & $\begin{array}{l}\text { BAFF } \\
\text { APRIL }\end{array}$ & unexpected inflammatory effects [81] \\
\hline
\end{tabular}

tion [64]. Eliminating the T-cell activating, antigen-presenting functions of B-cells by way of B-cell depletion, likely reduces intraparenchymal inflammatory effectors to a degree that will render autoantibodies ineffective promoters of tissue damage. Overall, memory B-cells and plasmablasts/plasma cells are the most abundant B-cell subsets in the CNS and CSF of MS patients. However, these B-cells do not represent a static immune response but rather engage in active affinity maturation with help from other immune cell types, cytokines, and survival factors.

\section{B-Cell-Depleting Therapy in MS}

CD20-targeting lymphocyte-depleting therapy was shown to effectively suppress MS disease activity measures, including the development of new enhancing lesions and relapse rates [4-7]. Beginning with the first studies that described the successful treatment of MS with the anti-CD20 antibody rituximab $[4,5]$, further efforts were made to explore B-cell depletion as therapeutic paradigm in MS. In the following paragraphs, we briefly discuss emerging therapies that were developed to directly target B-cells: anti-CD19, anti-CD20, and anti-BAFF-R (table 1). All are IgG1 antibodies and can mediate complement-dependent (CDC) and antibody-dependent cellmediated (ADCC) cytotoxic effects on their target cells.

\section{Anti-CD20 Therapy}

Three monoclonal anti-CD20 antibodies have been or are currently being studied for the treatment of MS: rituximab (chimeric human/mouse IgG1), ocrelizumab (humanized IgG1), and ofatumumab (fully human IgG1); they differ in their recognition of CD20 epitopes and in the intensity of CDC or ADCC elicited, but all mediate near-complete depletion of CD20+ B-cells in peripheral blood (reviewed in [65]). Very low numbers of B-cells remain in the circulation following CD20-targeted depletion [66], and certain B-cell populations resident in lymphoid tissues may also display resistance to B- cell depleting therapies [67]. CD20 is expressed on a wide range of $\mathrm{B}$-cell subsets starting at the pre-B-cell stage and extending through to memory B-cells (fig. 3). Accordingly, proB-cells and antibody-producing plasmablasts/plasma cells are not primarily affected by anti-CD20 therapy; levels of soluble immunoglobulins in serum $[5,6]$ remain mostly unchanged, at least in the short-term. Rituximab was shown to reduce CSF B-cell counts, but at 6 months the OCB and CSF IgG-Index remained unchanged [68]. 


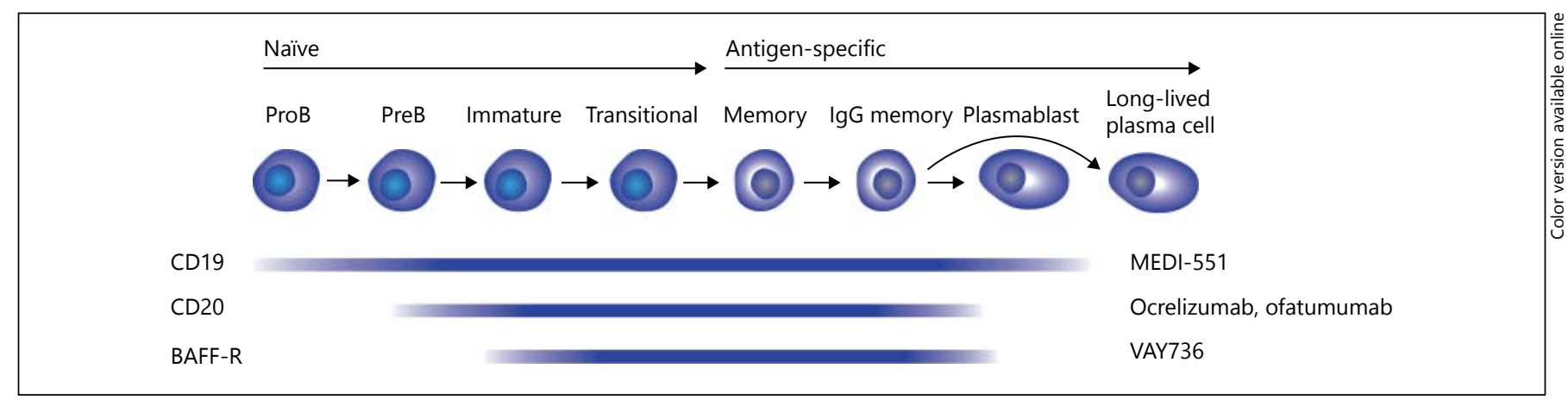

Fig. 3. B-cell development and expression of surface markers targeted by emerging MS therapeutics. CD19 is a pan-B-cell marker expressed on nearly the entire B-cell lineage starting from early pro-B-cells and disappearing on long-lived plasma cells; MEDI551 (anti-CD19 antibody) currently in clinical development for MS therapy cuts deeply into the B-cell compartment. CD20 is ex-

Anti-CD20-mediated B-cell depletion using rituximab represents the first effort at directly targeting B-cells in MS $[4,5]$. In the 48-week phase II trial [5], patients who received rituximab had a highly significant $>90 \%$ reduction in total gadolinium-enhancing lesions on brain MRI over the course of the study, beginning at week 12; clinically, a significant relapse-rate reduction of about $50 \%$ was observed at 24 and 48 weeks [5]. At 48 weeks, $24.1 \%$ of patients tested for the presence of human anti-chimeric antibodies (HACA, i.e., antibodies against rituximab) had developed HACA without apparent association with efficacy measures. The phase II trials with ocrelizumab and ofatumumab cite similar highly statistically significant reduction in the numbers of new and total gadolinium-enhancing lesions [6,7]; ocrelizumab resulted in relapse rate reductions between 73 and 80\% [6]. Ocrelizum$\mathrm{ab}$ is currently in phase III clinical development for RRMS and primary progressive MS (ClinicalTrials.gov Identifiers: NCT01247324, NCT01412333, and NCT01194570). As detailed earlier in this article, multiple functions of B-cells can be affected by anti-CD20-mediated B-cell depletion. The long-term effects of anti-CD20 therapy in MS have yet to be fully understood, both in terms of efficacy and safety. Ocrelizumab was reported to result in sustained suppression of clinical MRI disease-activity 72 weeks after the last of 4 dosages applied at 24-week intervals [24]. Over the short-term, anti-CD20 therapy can result in mostly mildly reduced serum immunoglobulin levels; however, prolonged exposure to anti-CD20 antibodies may induce delayed depletion of the plasma cell population and reduction of soluble immunoglobulins due to reduced memory B-cell formation and terminal pressed on the majority of B-cells; it appears on pre-B-cells and becomes downregulated during terminal differentiation to plasmablasts/plasma cells. Interestingly, CD20 is also expressed by a small subset of T-cells, which become depleted by rituximab. BAFF-R has a similar expression pattern as CD20; VAY736 is also being studied now as a therapy for MS.

differentiation into antibody-producing subsets [69]. Taken together, the clinical evidence demonstrates that CD20-targeting therapy is highly effective in reducing MRI disease-activity outcome measures and phase III clinical trials are expected to fully reveal the therapeutic potential of this approach.

Interestingly, CD20 was also reported to be expressed at low levels in a small subset of T-cells $[66,70]$ in healthy donors and patients with rheumatoid arthritis (RA); rituximab effectively depletes these $\mathrm{T}$-cells from the peripheral blood of RA patients [71]. CD20-expressing Tcells are likely functionally diverse but harbor proinflammatory Th17 properties in RA [72]. Our own work confirms the depletion of $\mathrm{CD} 3+\mathrm{CD} 20^{\mathrm{dim}} \mathrm{T}$-cells from the peripheral blood of MS patients treated with rituximab [66]. Clearly, further work is necessary to determine whether CD20-expressing T-cells contribute to MS immune pathology.

\section{Anti-CD19 Therapy}

More recently, a humanized anti-CD19 IgG1 antibody [73] MEDI-551, entered phase II clinical development for the treatment of MS (ClinicalTrials.gov Identifier: NCT01585766). At this point, no data for MEDI-551 in MS have been reported. CD19 is expressed on B-cells starting with pro-B-cells through the antibody-producing plasmablast stage (fig. 3), and is gradually lost during terminal differentiation to plasma cells [74]. In an animal model with humanized CD19 and CD20, MEDI-551 induced longer-lasting $\mathrm{B}$-cell depletion compared to rituximab due to significant effects on early B-cells (pro-Bcells) in the bone marrow [73]. Also in animals, it was 
shown that anti-CD19 therapy reduces levels of serum immunoglobulins including autoantibodies due to plasmablast/plasma cell depletion [75]. It is unclear whether autoantibodies play a significant role in MS immune pathology and whether the enhanced antibody-reducing functionality of MEDI-551 will provide increased efficacy and/or risk of infection compared to anti-CD20 therapy. Aside from the effect on plasmablasts and plasma cells and slower B-cell repopulation after treatment, MEDI551 is expected to affect the same B-cell functions as CD20-targeting strategies. Anti-CD19 therapy will not deplete $\mathrm{CD} 3+\mathrm{CD} 20^{\mathrm{dim}} \mathrm{T}$-cells; however, a small number of reports describe CD19-expressing dendritic cells [74, 76], but their existence in humans has not been diligently studied and the potential effect of anti-CD19 therapy on dendritic cells is merely speculative at this point.

\section{Anti-BAFF-R Therapy}

The most recent addition to the armamentarium of biologics directly targeting B-cells is VAY736, a fully human IgG1 antibody against the B-cell activating factorreceptor (BAFF-R), currently in phase II clinical developmentforMS(ClinicalTrials.govIdentifier:NCT02038049). In healthy humans, BAFF-R is expressed on naïve B-cells and can be found through post-germinal center memory B-cell and plasma blast stages (fig. 3) [77]. Low levels of BAFF-R have also been described in human central and effector T-cells [78]. BAFF-R is the receptor for BAFF (also known as BLyS, B lymphocyte stimulator); BAFF promotes B-cell survival at numerous stages throughout B-cell development. In MS, BAFF was found to be elevated in demyelinating lesions [44], and has also been suggested to be involved in the formation of lymphoid follicle-like meningeal structures [42]. Interestingly, therapeutic targeting and neutralization of soluble BAFF and APRIL (A Proliferation-Inducing Ligand), which is another B-cell stimulator, by atacicept lead to increased inflammatory activity in MS [79]. No data has been reported regarding the biological effects of VAY736 in humans. However, given the fact that its IgG1 isotype can induce $\mathrm{CDC}$ and ADCC, and that BAFF-R is expressed on a wide range of B-cell subsets, VAY736 may likely show similar effects on the B-cell compartment as anti-CD20 antibodies but may also lead to reduced serum immunoglobulin levels. Like anti-CD20 antibodies, VAY736 may induce depletion of a small portion of T-cells, which may or may not be of therapeutic relevance. Theoretically, VAY736 could exert additional effects by blocking BAFF binding to BAFF-R on B-cells that escape depletion in peripheral blood and lymphoid tissues, and may therefore interfere with a similar immunological pathway as atacicept, that is, BAFF/BAFF-R interaction. However, atacicept was designed to target and neutralize soluble B-cell activation factors, while VAY736 appears to have been developed to primarily target B-cells for depletion, illustrating a different mode of action. In this context, it is interesting to note that BAFF-R-deficient mice have fewer mature B-cells [80] and develop increased EAE severity [81], a scenario that probably mirrors the effects of atacicept in humans.

\section{Summary}

B-cells play important roles in the initiation and perpetuation of CNS-targeting inflammation in MS. There are overlapping B-cell repertoires on both sides of the blood-brain barrier, suggesting that disease-driving immunological stimuli are active not only in the CNS but also in the periphery. Multiple B-cell mediated mechanisms are likely involved in MS immune pathology, with antigen-presentation by B-cells occupying a central role. $\mathrm{B}$-cell depletion is a highly effective and promising therapeutic approach for MS. Four different biologic agents that directly target B-cells for depletion are currently in clinical development, two targeting CD20, one targeting $\mathrm{CD} 19$, and one targeting the BAFF-R. The common denominator for each of these therapeutic approaches is the depletion of the B-cell compartment (although this remains to be formally demonstrated for the anti-BAFF-R). However, each strategy also has its unique features, which may or may not contribute to differences in therapeutic efficacy and/or safety profiles. Additional work is required to further delineate the features of pathologically relevant B-cells and their target antigens in MS.

\section{Funding and Disclosures}

Dr. von Büdingen is supported by grants from the NMSS (RG4868), and the NIH (K02NS072288), and by an endowment from the Rachleff Family Foundation. He has received research funding from Pfizer and Roche, and consulting fees from Novartis and Roche. Dr. Zamvil is supported by research grants from the NIH (R01AI073737 and R01NS063008), the NMSS (RG-4124), the Guthy Jackson Charitable Foundation, the Maisin Foundation, Biogen Idec Inc., Teva Pharmaceuticals Inc., Five Prime Inc. and Boehringer-Ingelheim Inc. He has served as a consultant and received honoraria from Biogen-Idec, EMD-Serono, Genzyme, Novartis, Questcor, Roche, and Teva Pharmaceuticals, and has served or currently serves on Data Safety Monitoring Boards for Lilly, BioMS, Teva and Opexa Therapeutics. Dr. Palanichamy is an employee of Biogen. K. LehmannHorn received fellowship grants from the Deutsche Forschungsgemeinschaft (DFG; Le 3079/1-1) and the NMSS (FG 2067). von Büdingen/Palanichamy/ Lehmann-Horn/Michel/Zamvil 


\section{References}

1 Compston A, Coles A: Multiple sclerosis. Lancet 2008;372:1502-1517.

2 Orton SM, Herrera BM, Yee IM, et al: Sex ratio of multiple sclerosis in Canada: a longitudinal study. Lancet Neurol 2006;5:932936.

3 Hauser SL, Oksenberg JR: The neurobiology of multiple sclerosis: genes, inflammation, and neurodegeneration. Neuron 2006;52:6176.

4 Bar-Or A, Calabresi PA, Arnold D, et al: Rituximab in relapsing-remitting multiple sclerosis: a 72-week, open-label, phase I trial. Ann Neurol 2008;63:395-400.

5 Hauser SL, Waubant E, Arnold DL, et al: Bcell depletion with rituximab in relapsing-remitting multiple sclerosis. N Engl J Med 2008; 358:676-688.

6 Kappos L, Li D, Calabresi PA, et al: Ocrelizumab in relapsing-remitting multiple sclerosis: a phase 2, randomised, placebo-controlled, multicentre trial. Lancet 2011;378 1779-1787.

7 Sorensen PS, Lisby S, Grove R, et al: Safety and efficacy of ofatumumab in relapsing-remitting multiple sclerosis: a phase 2 study. Neurology 2014;82:573-581.

8 Genain CP, Nguyen MH, Letvin NL, et al: Antibody facilitation of multiple sclerosis-like lesions in a nonhuman primate. J Clin Invest 1995;96:2966-2974.

9 Linington C, Engelhardt B, Kapocs G, Lassman $\mathrm{H}$ : Induction of persistently demyelinated lesions in the rat following the repeated adoptive transfer of encephalitogenic $\mathrm{T}$ cells and demyelinating antibody. J Neuroimmunol 1992;40:219-224.

10 Lyons JA, Ramsbottom MJ, Cross AH: Critical role of antigen-specific antibody in experimental autoimmune encephalomyelitis induced by recombinant myelin oligodendrocyte glycoprotein. Eur J Immunol 2002;32: 1905-1913.

11 Schluesener HJ, Sobel RA, Linington C, Weiner HL: A monoclonal antibody against a myelin oligodendrocyte glycoprotein induces relapses and demyelination in central nervous system autoimmune disease. J Immunol 1987; 139:4016-4021.

12 Lyons JA, San M, Happ MP, Cross AH: B cells are critical to induction of experimental allergic encephalomyelitis by protein but not by a short encephalitogenic peptide. Eur J Immunol 1999;29:3432-3439.

13 Molnarfi N, Schulze-Topphoff U, Weber MS, et al: MHC class II-dependent B cell APC function is required for induction of CNS autoimmunity independent of myelinspecific antibodies. J Exp Med 2013;210: 2921-2937.

14 Weber MS, Prod'homme T, Patarroyo JC, et al: B-cell activation influences $T$-cell polarization and outcome of anti-CD20 b-cell depletion in central nervous system autoimmunity. Ann Neurol 2010;68:369-383.
15 Wardemann H, Yurasov S, Schaefer A, Young JW, Meffre E, Nussenzweig MC: Predominant autoantibody production by early human B cell precursors. Science 2003;301: 1374-1377.

16 Mouquet H, Scheid JF, Zoller MJ, et al: Polyreactivity increases the apparent affinity of anti-HIV antibodies by heteroligation. Nature 2010;467:591-595.

17 Kinnunen T, Chamberlain N, Morbach H, et al: Specific peripheral B cell tolerance defects in patients with multiple sclerosis. J Clin Invest 2013;123:2737-2741.

18 Stern JN, Yaari G, Vander Heiden JA, et al: B cells populating the multiple sclerosis brain mature in the draining cervical lymph nodes. Sci Transl Med 2014;6:248ra107.

19 Berer K, Mues M, Koutrolos M, et al: Commensal microbiota and myelin autoantigen cooperate to trigger autoimmune demyelination. Nature 2011;479:538-541.

20 Bar-Or A, Oliveira EM, Anderson DE, et al: Immunological memory: contribution of memory B cells expressing costimulatory molecules in the resting state. J Immunol 2001;167:5669-5677.

21 Duddy M, Niino M, Adatia F, et al: Distinct effector cytokine profiles of memory and naive human B cell subsets and implication in multiple sclerosis. J Immunol 2007; 178:60926099.

22 Harp CT, Ireland S, Davis LS, et al: Memory $B$ cells from a subset of treatment-naïve relapsing-remitting multiple sclerosis patients elicit CD4(+) T-cell proliferation and IFN- $\gamma$ production in response to myelin basic protein and myelin oligodendrocyte glycoprotein. Eur J Immunol 2010;40:2942-2956.

23 Roll P, Palanichamy A, Kneitz C, Dorner T, Tony HP: Regeneration of B cell subsets after transient B cell depletion using anti-CD20 antibodies in rheumatoid arthritis. Arthritis Rheum 2006;54:2377-2386.

24 Hauser S, Li D, Calabresi P, et al. (eds): Week 144 Results of a Phase II, Randomized, Multicenter Trial Assessing the Safety and Efficacy of Ocrelizumab in Patients with Relapsing-Remitting Multiple Sclerosis (RRMS) (S31.004). San Diego, CA, 2013.

25 Barr TA, Shen P, Brown S, et al: B cell depletion therapy ameliorates autoimmune disease through ablation of IL-6-producing B cells. J Exp Med 2012;209:1001-1010.

26 Leandro MJ, Cambridge G, Ehrenstein MR, Edwards JC: Reconstitution of peripheral blood B cells after depletion with rituximab in patients with rheumatoid arthritis. Arthritis Rheum 2006;54:613-620.

27 Bar-Or A, Fawaz L, Fan B, et al: Abnormal Bcell cytokine responses a trigger of T-cell-mediated disease in MS? Ann Neurol 2010;67: $452-461$.

28 Correale J, Fiol M, Gilmore W: The risk of relapses in multiple sclerosis during systemic infections. Neurology 2006;67:652-659.
29 Buljevac D, Flach HZ, Hop WC, et al: Prospective study on the relationship between infections and multiple sclerosis exacerbations. Brain 2002; 125:952-960.

30 Blair PA, Norena LY, Flores-Borja F, et al: CD19(+)CD24(hi)CD38(hi) B cells exhibit regulatory capacity in healthy individuals but are functionally impaired in systemic lupus erythematosus patients. Immunity 2010;32: 129-140.

31 Matsushita T, Yanaba K, Bouaziz JD, Fujimoto M, Tedder TF: Regulatory B cells inhibit EAE initiation in mice while other B cells promote disease progression. J Clin Invest 2008; 118:3420-3430.

32 Iwata Y, Matsushita T, Horikawa M, et al: Characterization of a rare IL-10-competent B-cell subset in humans that parallels mouse regulatory B10 cells. Blood 2011;117:530541.

33 Yoshizaki A, Miyagaki T, DiLillo DJ, et al: Regulatory B cells control T-cell autoimmunity through IL-21-dependent cognate interactions. Nature 2012;491:264-268.

34 Lehmann-Horn K, Schleich E, Hertzenberg D, et al: Anti-CD20 B-cell depletion enhances monocyte reactivity in neuroimmunological disorders. J Neuroinflammation 2011;8:146.

35 Palanichamy A, Apeltsin L, Kuo TC, et al: Immunoglobulin class-switched B cells form an active immune axis between CNS and periphery in multiple sclerosis. Sci Transl Med 2014; 6:248ra106

36 von Büdingen HC, Kuo TC, Sirota M, et al: B cell exchange across the blood-brain barrier in multiple sclerosis. J Clin Invest 2012;122: 4533-4543.

37 Bankoti J, Apeltsin L, Hauser SL, et al: In multiple sclerosis, oligoclonal bands connect to peripheral B-cell responses. Ann Neurol 2014;75:266-276

38 Frischer JM, Bramow S, Dal-Bianco A, et al: The relation between inflammation and neurodegeneration in multiple sclerosis brains. Brain 2009; 132:1175-1189.

39 Serafini B, Rosicarelli B, Magliozzi R, Stigliano E, Aloisi F: Detection of ectopic B-cell follicles with germinal centers in the meninges of patients with secondary progressive multiple sclerosis. Brain Pathol 2004;14:164-174.

40 Howell OW, Reeves CA, Nicholas R, et al: Meningeal inflammation is widespread and linked to cortical pathology in multiple sclerosis. Brain 2011;134:2755-2771.

41 Magliozzi R, Howell OW, Reeves C, et al: A gradient of neuronal loss and meningeal inflammation in multiple sclerosis. Ann Neurol 2010;68:477-493.

42 Magliozzi R, Columba-Cabezas S, Serafini B, Aloisi F: Intracerebral expression of CXCL13 and BAFF is accompanied by formation of lymphoid follicle-like structures in the meninges of mice with relapsing experimental autoimmune encephalomyelitis. J Neuroimmunol 2004; 148:11-23. 
43 Krumbholz M, Theil D, Cepok S, et al: Chemokines in multiple sclerosis: CXCL12 and CXCL13 up-regulation is differentially linked to CNS immune cell recruitment. Brain 2006; 129:200-211.

44 Krumbholz M, Theil D, Derfuss T, et al: BAFF is produced by astrocytes and up-regulated in multiple sclerosis lesions and primary central nervous system lymphoma. J Exp Med 2005; 201:195-200.

45 Baranzini SE, Jeong MC, Butunoi C, Murray RS, Bernard CC, Oksenberg JR: B cell repertoire diversity and clonal expansion in multiple sclerosis brain lesions. J Immunol 1999; 163:5133-5144.

46 Owens GP, Ritchie AM, Burgoon MP, Williamson RA, Corboy JR, Gilden DH: Singlecell repertoire analysis demonstrates that clonal expansion is a prominent feature of the $\mathrm{B}$ cell response in multiple sclerosis cerebrospinal fluid. J Immunol 2003;171:2725-2733.

47 Qin Y, Duquette P, Zhang Y, Talbot P, Poole $\mathrm{R}$, Antel J: Clonal expansion and somatic hypermutation of $\mathrm{V}(\mathrm{H})$ genes of $\mathrm{B}$ cells from cerebrospinal fluid in multiple sclerosis. J Clin Invest 1998;102:1045-1050.

48 Sandberg-Wollheim M, Turesson I: Lymphocyte subpopulations in the cerebrospinal fluid and peripheral blood in patients with multiple sclerosis. Scand J Immunol 1975;4:831-836.

49 Ritchie AM, Gilden DH, Williamson RA, et al: Comparative analysis of the CD19+ and $\mathrm{CD} 138+$ cell antibody repertoires in the cerebrospinal fluid of patients with multiple sclerosis. J Immunol 2004;173:649-656.

50 Colombo M, Dono M, Gazzola P, et al: Accumulation of clonally related $\mathrm{B}$ lymphocytes in the cerebrospinal fluid of multiple sclerosis patients. J Immunol 2000;164:2782-2789.

51 Smith-Jensen T, Burgoon MP, Anthony J, Kraus H, Gilden DH, Owens GP: Comparison of immunoglobulin $\mathrm{G}$ heavy-chain sequences in MS and SSPE brains reveals an antigen-driven response. Neurology 2000;54:1227-1232.

52 Beltrán E, Obermeier B, Moser M, et al: Intrathecal somatic hypermutation of IgM in multiple sclerosis and neuroinflammation. Brain 2014;137:2703-2714.

53 Lovato L, Willis SN, Rodig SJ, et al: Related B cell clones populate the meninges and parenchyma of patients with multiple sclerosis. Brain 2011;134:534-541.

54 Obermeier B, Lovato L, Mentele R, et al: Related $\mathrm{B}$ cell clones that populate the CSF and CNS of patients with multiple sclerosis produce CSFimmunoglobulin. J Neuroimmunol 2011;233:245-248.

55 Corcione A, Casazza S, Ferretti E, et al: Recapitulation of $B$ cell differentiation in the central nervous system of patients with multiple sclerosis. Proc Natl Acad Sci U S A 2004;101: 11064-11069.
56 Obermeier B, Mentele R, Malotka J, et al: Matching of oligoclonal immunoglobulin transcriptomes and proteomes of cerebrospinal fluid in multiple sclerosis. Nat Med 2008; 14:688-693.

57 von Büdingen $\mathrm{HC}$, Gulati M, Kuenzle S, Fischer K, Rupprecht TA, Goebels N: Clonally expanded plasma cells in the cerebrospinal fluid of patients with central nervous system autoimmune demyelination produce 'oligoclonal bands'. J Neuroimmunol 2010; 218:134-139.

58 Cepok S, Rosche B, Grummel V, et al: Shortlived plasma blasts are the main B cell effector subset during the course of multiple sclerosis. Brain 2005;128:1667-1676.

59 Haas J, Bekeredjian-Ding I, Milkova M, et al: $B$ cells undergo unique compartmentalized redistribution in multiple sclerosis. J Autoimmun 2011;37:289-299.

60 Kostulas VK, Link H, Lefvert AK: Oligoclonal IgG bands in cerebrospinal fluid. Principles for demonstration and interpretation based on findings in 1114 neurological patients. Arch Neurol 1987;44:1041-1044.

61 Villar LM, Masjuan J, Gonzalez-Porque P, et al: Intrathecal IgM synthesis predicts the onset of new relapses and a worse disease course in MS. Neurology 2002;59:555-559.

62 Sindic CJ, Monteyne P, Laterre EC: Occurrence of oligoclonal IgM bands in the cerebrospinal fluid of neurological patients: an immunoaffinity-mediated capillary blot study. J Neurol Sci 1994;124:215-219.

63 Lucchinetti C, Bruck W, Parisi J, Scheithauer B, Rodriguez M, Lassmann H: Heterogeneity of multiple sclerosis lesions: implications for the pathogenesis of demyelination. Ann Neurol 2000;47:707-717.

64 Saadoun S, Waters P, Bell BA, Vincent A, Verkman AS, Papadopoulos MC: Intra-cerebral injection of neuromyelitis optica immunoglobulin $G$ and human complement produces neuromyelitis optica lesions in mice. Brain 2010;133:349-361.

65 Robak T, Robak E: New anti-CD20 monoclonal antibodies for the treatment of B-cell lymphoid malignancies. BioDrugs 2011;25:1325.

66 Palanichamy A, Jahn S, Nickles D, et al: Rituximab efficiently depletes increased CD20-expressing $\mathrm{T}$ cells in multiple sclerosis patients. J Immunol 2014;193:580-586.

67 Gong Q, Ou Q, Ye S, et al: Importance of cellular microenvironment and circulatory dynamics in B cell immunotherapy. J Immunol 2005;174:817-826.
68 Cross AH, Stark JL, Lauber J, Ramsbottom MJ, Lyons JA: Rituximab reduces B cells and $\mathrm{T}$ cells in cerebrospinal fluid of multiple sclerosis patients. J Neuroimmunol 2006;180:6370.

69 Brinkman IH, van de Laar MA, Jansen TL, van Roon EN: The potential risk of infections during (prolonged) rituximab therapy in rheumatoid arthritis. Expert Opin Drug Saf 2011;10:715-726.

70 Hultin LE, Hausner MA, Hultin PM, Giorgi JV: CD20 (pan-B cell) antigen is expressed at a low level on a subpopulation of human $\mathrm{T}$ lymphocytes. Cytometry 1993;14:196-204.

71 Wilk E, Witte T, Marquardt N, et al: Depletion of functionally active CD20+ T cells by rituximab treatment. Arthritis Rheum 2009; 60:3563-3571.

72 Eggleton P, Bremer E, Tarr JM, et al: Frequency of Th17 CD20+ cells in the peripheral blood of rheumatoid arthritis patients is higher compared to healthy subjects. Arthritis Res Ther 2011;13:R208.

73 Herbst R, Wang Y, Gallagher S, et al: B-cell depletion in vitro and in vivo with an afucosylated anti-CD19 antibody. J Pharmacol Exp Ther 2010;335:213-222.

74 Tedder TF: CD19: a promising B cell target for rheumatoid arthritis. Nat Rev Rheumatol 2009;5:572-577.

75 Yazawa N, Hamaguchi Y, Poe JC, Tedder TF: Immunotherapy using unconjugated CD19 monoclonal antibodies in animal models for B lymphocyte malignancies and autoimmune disease. Proc Natl Acad Sci U S A 2005; 102 : 15178-15183.

76 Munn DH, Sharma MD, Hou D, et al: Expression of indoleamine 2,3-dioxygenase by plasmacytoid dendritic cells in tumor-draining lymph nodes. J Clin Invest 2004;114:280-290.

77 Carter RH, Zhao H, Liu X, et al: Expression and occupancy of BAFF-R on B cells in systemic lupus erythematosus. Arthritis Rheum 2005;52:3943-3954.

$78 \mathrm{Ng} \mathrm{LG}$, Sutherland AP, Newton R, et al: B cellactivating factor belonging to the TNF family (BAFF)- $\mathrm{R}$ is the principal BAFF receptor facilitating BAFF costimulation of circulating $\mathrm{T}$ and B cells. J Immunol 2004;173:807-817.

79 Hartung HP, Kieseier BC: Atacicept: targeting B cells in multiple sclerosis. Ther Adv Neurol Disord 2010;3:205-216.

80 Sasaki Y, Casola S, Kutok JL, Rajewsky K, Schmidt-Supprian M: TNF family member B cell-activating factor (BAFF) receptor-dependent and -independent roles for BAFFin B cell physiology. J Immunol 2004;173:22452252.

81 Kim SS, Richman DP, Zamvil SS, Agius MA: Accelerated central nervous system autoimmunity in BAFF-receptor-deficient mice. J Neurol Sci 2011;306:9-15. 